\title{
SOM LIVRE: MUDAR OU MORRER?
}

\section{José Luiz Trinta}

Ibmec - RJ

\section{Joyce Gonçalves Altaf}

Instituto Vianna Júnior

\section{Márcio Moutinho Abdalla}

Universidade Federal Fluminense

\section{Irene Raguenet Troccoli}

Universidade Estácio de Sá

\section{Introdução}

A gravadora brasileira Som Livre, empresa das Organizações Globo S/A, foi fundada em 1969, no Rio de Janeiro, com a missão específica de atender uma demanda relacionada à parte musical da programação da emissora de televisão do grupo. Seu fundador foi o produtor musical João Araújo, pai do cantor Cazuza. Durante décadas, sua atuação em um mercado maduro e estável foi simples, objetiva e lucrativa. No final da década de 1990, com a adoção de uma estratégia de diversificação, a empresa experimentou a internacionalização, ingressou no mundo virtual e investiu em operações que suportassem suas escolhas.

\section{CFGV-EAESP/RAE 2011}

Todos os direitos reservados. Permitidas a citação e a reprodução parcial ou total, desde que identificada a fonte. Em caso de dúvidas, consulte a Redação: gvcasos.redacao@fgv.br; (11) 3799-3717 
Contudo, em 1999, a Som Livre começou a se distanciar de seu escopo inicial, adotando uma estratégia de diversificação que tornou seu foco difuso. Nessa fase, o número de lançamentos cresceu significativamente, o que ampliou, em igual proporção, as chances de insucesso. Em 2003, a empresa experimentou seu primeiro resultado financeiro negativo, que coincidiu com o auge da crise das organizações Globo. Era o marco inicial de uma fase problemática.

Em meados de 2005, após ter resolvido parte dos problemas, o novo presidente resolveu colocar a seguinte questão para a sua equipe: "Em um mercado onde o fonograma (gravação da música) é desejado pelo consumidor, mas tem valor próximo a zero em qualquer plataforma (CD, DVD, celular, MP3 player), de que forma poderemos sobreviver como empresa?". A pergunta intrigou os membros da diretoria, que se depararam com a quebra de antigos paradigmas e se viram obrigados a repensar um bem-sucedido negócio, que vinha sucumbindo com a evolução tecnológica, que tinha na internet um novo marco de negócios.

Em uma situação como essa, redefinir o norte da empresa não se configurava em uma tarefa simples. Surgiu, então, uma proposta de mudança de posicionamento estratégico da empresa: deixar de dar ênfase às vendas de produtos (principalmente CDs e DVDs) e priorizar serviços associados à música.

\section{Um pouco da história}

A Som Livre iniciou sua história com a premissa de desenvolver e de comercializar trilhas sonoras das novelas e dos programas produzidos pela TV Globo. A empresa fora concebida com raízes musicais fortes, uma vez que seu fundador já atuava como produtor musical.

Com o tempo, além das trilhas sonoras, a Som Livre expandiu seu catálogo com coletâneas, com gravações exclusivas de artistas nacionais e estrangeiros, e com projetos culturais. Uma diversidade de grandes nomes da música popular brasileira, além de outros gêneros, já figuraram em seu elenco, entre eles Rita Lee, Lulu Santos, Cazuza, Tim Maia, Barão Vermelho, Gal Costa, Elis 
Regina, Djavan e Xuxa. Pode-se seguramente dizer que boa parte da história da música brasileira teve forte participação da Som Livre.

Durante 30 anos, a empresa vivenciou intensa e contínua evolução, sendo um dos principais nomes da indústria fonográfica nacional. Em muitos momentos, a organização apenas trabalhava em prol da manutenção do status quo. Administrar a Som Livre não era nenhuma tarefa hercúlea, haja vista que a concorrência era pacífica e a disputa ocorria de igual para igual.

Entretanto, a partir de 1999, com a invenção do sistema peer-to-peer (P2P), que permite a troca de arquivos on-line (o marco foi o lançamento do Napster), o mercado fonográfico nunca mais seria o mesmo. A Som Livre e outras empresas lançaram sites, mas o foco estava em vender produtos e não prover serviços. Nesse mesmo ano, a Som Livre começou a vivenciar problemas diversos, que se mostraram incisivos até o ano de 2005, quando a nova diretoria assumiu a empresa, tendo à frente Leonardo Ganem. Desde então, a administração da Som Livre persegue uma solução para sua problemática. Atualmente, a Som Livre continua sendo uma subsidiária da TV Globo, também presente no mercado musical, desenvolvendo e atuando na produção e venda de CDs, de DVDs e de ring tones para celular, e na distribuição eletrônica de música. Com capacidade para cerca de 80 lançamentos por ano, a empresa concentra-se em produtos relacionados com os programas das Organizações Globo, como CDs de trilhas de novelas e outros programas, e DVDs de programas da TV Globo, como licenciada da Globo Marcas.

Em 2008, a gravadora criou o subselo Som Livre Apresenta (posteriormente rebatizado de SLAP), com o intuito de lançar novos artistas e projetos inéditos de artistas consagrados. Em 2009, a empresa teve sua logomarca redesenhada, marcando a campanha de comemoração dos 40 anos de existência da organização.

\section{O início dos problemas...}

Na virada do século, a Som Livre experimentava novas oportunidades de negócios e, mediante uma tentativa de diversificação, afastava-se do seu core business. Assim, o selo ganhou distanciamento 
da Rede Globo de Televisão, e a Som Livre passou a lançar todos os tipos de artistas. O número de lançamentos aumentou, de uma média de 80, para 180 ao ano, sobrecarregando a estrutura operacional da empresa e tornando o risco de insucesso extremamente alto. Lançar um cantor que tinha uma música conhecida na novela principal era garantia de retorno do investimento, modelo esse que a empresa conhecia bem. Porém, apostar em novidades e competir em preços, dividir espaços nas lojas e conseguir mídia fora da TV Globo era completamente diferente, com resultados incertos.

Com essa decisão, a editora musical do grupo passou a ser mantida como um simples catálogo, sem apoio comercial da Rede Globo, o que a colocou no mesmo patamar comercial de suas concorrentes.

Aliado à estratégia de diversificação musical, foram criadas três empresas com desafios distintos:

- A Som Livre Portugal, que seguia o mesmo modelo de negócios utilizado pela matriz brasileira com a Rede Globo, operando com a TV SIC;

- A somlivre.com, que se configurava em um varejista virtual e que, com o tempo, expandiu sua linha de produtos, como livros e suprimentos de informática; e

- A Zende, uma operadora logística criada com fins de dar suporte à somlivre.com.

A ampliação do escopo, que levou à perda do foco principal da empresa, aliada ao declínio generalizado do mercado, gerou resultados inesperados. A Som Livre apresentou, em 2003, o primeiro resultado negativo de toda sua história. Não bastasse essa situação, os prejuízos coincidiram com o auge da crise das Organizações Globo, que, no ano, encontravam-se fortemente endividadas em moedas estrangeiras e sofriam os solavancos econômicos em virtude do súbito aumento da cotação do dólar. Os resultados não tardaram a aparecer e indicaram que a opção estratégica pela diversificação, junto a uma mudança mercadológica extrema, não levou a empresa a uma situação financeira alentadora. 


\section{Reconhecendo a crise}

Foi nesse cenário que a nova diretoria da Som Livre assumiu a empresa, no final de 2004. Com a experiência adquirida nos anos trabalhados em grandes companhias de consultoria estratégica, o recém-empossado presidente, Leonardo Ganem, adotou, como primeira medida, a suspensão de todos os pagamentos e o recolhimento de todas as procurações que permitiam, a alguns funcionários, assinarem pela Som Livre. O pensamento era único: "Se não sei quanto será o meu faturamento, preciso ter certeza de quanto será minha despesa”. Após essa medida inicial, com a rápida regularização dos recebimentos e dos pagamentos, o fluxo de caixa estava sob controle.

Restava, então, definir as linhas de ação para o quadriênio 2004-2007. Foram duas as propostas, cujas descrições e resultados estão expostas no Anexo 1 (ver todas as linhas de ação adotadas pela Som Livre).

Como resultado direto da implementação dessas linhas de ação, a Som Livre enviou para as Organizações Globo, em 2005, mais dinheiro do que nos últimos seis anos somados. Além disso, aumentou em 10 vezes o retorno sobre a mídia utilizada. Seria um final feliz, se não estivesse prevista a queda contínua do mercado de CDs no futuro, conforme aponta o Anexo 1.

Por isso, além das ações tomadas, a gravadora criou novas ofertas ao mercado baseadas no marketing de serviços. Essas ofertas de serviços atuaram como resposta às mudanças do ambiente de negócios e, dessa forma, procurava-se evitar um possível fim trágico (ver alterações de faturamento desse mercado no Anexo 2). Essa situação, foco principal do presente caso de estudo, tem como objetivo central responder ao desafio lançado pela nova diretoria em 2005: "Em um mercado onde o fonograma (gravação da música) é desejado pelo consumidor, mas tem valor próximo a zero em qualquer plataforma ou mídia (seja ela CD, DVD, celular, MP3 player ou outra qualquer), como vamos sobreviver enquanto empresa?". 


\section{CD: seria o fim dos tempos?}

A internet alterou a maneira de fazer e de experimentar música. Ela propiciou profundas mutações nos meios e nos processos de difusão das canções. Em menos de 10 anos,as gravadoras, de certa forma, perderam o controle do que é produzido, difundido e consumido. Os artistas passaram a ter os shows como fonte maior de renda, mas as gravadoras tinham um desafio maior pela frente.

A cronologia dos eventos mais importantes, relacionados às mudanças sofridas pelo mercado fonográfico e pela gravadora Som Livre na última década, é demonstrada no Anexo 3.

\section{O que reserva o futuro?}

Como resposta à questão norteadora das estratégias da Som Livre, Leonardo Ganem propôs um intenso trabalho de análise, e a dúvida que restava em relação à sobrevivência da Som Livre em função do valor zero do fonograma foi desmembrada em duas respostas, como forma de atendimento à demanda:

a) There's no free lunch - quem pode pagar a conta do fonograma gratuito?

b) Que forma de música não pode ser copiada e, portanto, terá sempre valor?

Foram, então, propostos dois modelos de negócios para responder às questões colocadas:

a) Serviço B2B $\rightarrow$ associação da marca de grandes empresas à música independente.

b) Serviço B2C $\rightarrow$ eventos ao vivo com geração de conteúdo para a Rede Globo.

Começava, então, a se desenhar a migração de uma empresa vendedora de produtos para uma empresa prestadora de serviços. Ciente de todos os percalços que iriam enfrentar, Leonardo Ganem e sua equipe indagaram: "Como preparar a Som Livre para lidar com as alterações em cada uma dessas dimensões impostas pelos novos negócios?”. Em seu antigo modelo, as dimensões de serviços eram totalmente ignoradas, ao passo que, nessa nova fase, todas elas deveriam ser consideradas (ver detalhes dessa situação no Anexo 4). 
Não havia motivo para preocupações quanto às dimensões supracitadas. Tecnicamente, a Som Livre estava preparada para o desafio. Mas, para o novo modelo de negócios, era necessária uma visão diferente. Sentado em sua sala, Leonardo Ganem se perguntava: "Será mesmo esse o caminho? Estamos totalmente preparados para ele? Existe algo em que não pensamos? O negócio de prestação de serviços é muito diferente do que fazemos? Ou será que essa sempre foi a especialidade da Som Livre e nós não conseguíamos enxergar?".

\section{Questões para discussão}

1. Como você analisa a estratégia de diversificação adotada no final da década de 1990? Por que, embora seja uma estratégia funcional em muitas organizações, a Som Livre não obteve êxito?

2. Quais elementos do macroambiente de negócios afetaram diretamente o negócio da Som Livre? De que forma?

3. Analise o papel dos serviços agregados aos produtos tangíveis na busca por vantagem competitiva.

4. Como a Som Livre deve trabalhar as características de serviços em seu novo portfólio de negócio?

5. No papel de um consultor externo contratado pela Som Livre, discuta e crie argumentos favoráveis e desfavoráveis com base nos questionamentos finais de Leonardo Ganem. 


\section{Anexo 1}

\section{Linhas de ação adotadas pela Som Livre}

\begin{tabular}{|c|c|}
\hline \multicolumn{2}{|c|}{ LINHAS DE AÇÃO } \\
\hline Redirecionar negócios menores & Implementar melhorias operacionais \\
\hline $\begin{array}{l}\text { Melhorar, vender ou encerrar as atividades de } \\
\text { unidades que apresentassem: } \\
\text { - Baixa rentabilidade; } \\
\text { - Alto risco; } \\
\text { - Falta de alinhamento com a missão da Globo. }\end{array}$ & $\begin{array}{l}\text { Reestruturar a empresa ajustando cargos e } \\
\text { salários; } \\
\text { Implementar melhores práticas gerenciais; } \\
\text { Redefinir a estratégia de lançamentos; } \\
\text { Alinhar ações com a Rede Globo; } \\
\text { Otimizar o uso de mídia. }\end{array}$ \\
\hline \multicolumn{2}{|c|}{ RESULTADOS } \\
\hline $\begin{array}{l}\text { Somlivre.com reinventada (ativos vendidos por } \mathrm{R} \$ \\
2,5 \text { milhões); } \\
\text { Som Livre Portugal vendida (R\$ } 10 \text { milhões); } \\
\text { Parte do catálogo Sigem vendido ( } \mathrm{R} \$ 11 \text { milhões). }\end{array}$ & $\begin{array}{l}\text { Produtos alinhados com a Globo sobem de } 38 \% \\
\text { para } 80 \% \text { do total; } \\
\text { Margem bruta sobe de } 28 \% \text { para } 40 \% \text {; } \\
\text { Empresa volta a dar lucro. }\end{array}$ \\
\hline
\end{tabular}

Fonte: Entrevista

\section{Anexo 2}

\section{Mercado brasileiro de CDs (em milhares de $\mathbf{R} \$$ nominais)}

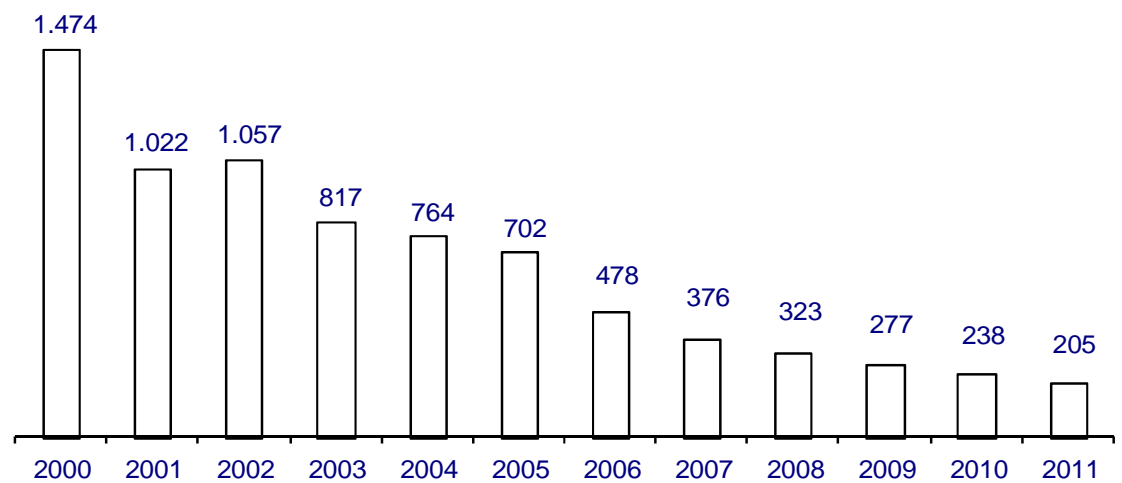

Fonte: Associação Brasileira de Produtores de Discos (ABPD), 2008 


\section{Anexo 3}

\section{Cronologia das mudanças sofridas no mercado fonográfico e na gravadora Som Livre}

\begin{tabular}{|c|c|}
\hline \multirow[t]{2}{*}{1999} & $\begin{array}{l}\text { Em maio, nasce o sistema peer-to-peer ( } \mathrm{P} 2 \mathrm{P}) \text {, que permite a troca de arquivos on-line. } \mathrm{O} \\
\text { principal deles, batizado de Napster, é lançado em maio e, em dezembro, processado pela } \\
\text { entidade que representa os interesses das gravadoras americanas (RIAA), por infringir } \\
\text { direitos autorais. }\end{array}$ \\
\hline & $\begin{array}{l}\text { A Som Livre lança seu site na internet. Em apenas quatro meses de operação, o site cresceu } \\
474 \% \text { em número de acessos. Foram mais de } 67 \text { mil unidades comercializadas e } 51 \text { mil } \\
\text { usuários cadastrados. }\end{array}$ \\
\hline \multirow[t]{2}{*}{2000} & $\begin{array}{l}\text { Em abril, a banda Metallica e o rapper Dr. Dre entram com ações contra o Napster. No } \\
\text { mesmo ano, a cantora Madonna, que havia se reunido com os executivos da companhia para } \\
\text { uma possível parceria, resolve processar a empresa. Em julho, as faixas do álbum "Kid A", do } \\
\text { Radiohead, caem na rede três meses antes do lançamento oficial. Quando chegou ao mercado, } \\
\text { o disco já tinha sido baixado por milhões de usuários. Mas, ao contrário do que a indústria } \\
\text { esperava, o Radiohead atingiu o topo de vendas pela primeira vez. }\end{array}$ \\
\hline & A Som Livre mantém seu site com muitos acessos e prossegue na venda de CDs pela internet. \\
\hline \multirow[t]{2}{*}{2001} & $\begin{array}{l}\text { Em outubro, um consórcio de estúdios de cinema e de gravadoras entra com ação contra as } \\
\text { três maiores empresas que sucederam o Napster: Kazaa, Morpheus e Grokster. Em dezembro, } \\
\text { um juiz federal dos Estados Unidos ordena que o Napster pare a circulação de } \\
\text { arquivos protegidos por direitos autorais. }\end{array}$ \\
\hline & $\begin{array}{l}\text { A Som Livre ganha o prêmio Ibrands de marcas mais lembradas quando se pensa em loja de } \\
\text { CD, vídeo e livro na internet. Com } 12 \% \text { do total de votos, a Som Livre deixou para trás a } \\
\text { marca virtual Submarino (7\%), além das tradicionais Saraiva (5\%) e Americanas }(3 \%) \text {. }\end{array}$ \\
\hline \multirow[b]{2}{*}{2002} & $\begin{array}{l}\text { Em fevereiro, surge o BitTorrent, tecnologia que divide o arquivo em diversas partes, } \\
\text { tornando o download mais rápido. Em junho, o Napster pede falência. }\end{array}$ \\
\hline & $\begin{array}{l}\text { Em maio, a Som Livre inicia um processo de digitalização do acervo, sendo a primeira } \\
\text { gravadora brasileira a comercializar suas músicas na forma de ringtones, além de } \\
\text { disponibilizar um acervo de } 17 \text { mil músicas para download. Em dezembro, a empresa começa } \\
\text { a vender CDs personalizados pela internet. }\end{array}$ \\
\hline \multirow[t]{2}{*}{2003} & $\begin{array}{l}\text { Em abril, a corte federal dos EUA decide que Kazaa, Morpheus e Grokster não podem ser } \\
\text { processados pelas infrações de direitos autorais cometidas pelos usuários. A alegação é que } \\
\text { empresas fornecem apenas o software e não determinam que uso (legal ou não) os internautas } \\
\text { fazem dele. Em setembro, a RIAA anuncia a primeira leva de ações contra indivíduos que } \\
\text { trocavam arquivos em redes P2P. Em outubro, o Napster ressurge como um serviço pago, } \\
\text { repassando dinheiro à indústria. }\end{array}$ \\
\hline & $\begin{array}{l}\text { Em novembro, a Som Livre, em sua loja virtual, passa a ofertar equipamentos de informática, } \\
\text { além dos produtos já ofertados, como livros, games, CDs e DVDs. }\end{array}$ \\
\hline \multirow[t]{2}{*}{2004} & $\begin{array}{l}\text { Em fevereiro, o Kazaa é processado civilmente por infração dos direitos autorais em uma } \\
\text { corte australiana. Em dezembro, a MPAA (associação dos estúdios de cinema norte- } \\
\text { americanos) anuncia ações contra usuários do BitTorrent. }\end{array}$ \\
\hline & $\begin{array}{l}\text { Ao final do ano, a Som Livre cria novas seções em seu site com o intuito de comercializar } \\
\text { produtos da empresa mãe - a Globo. }\end{array}$ \\
\hline \multirow[b]{2}{*}{2005} & $\begin{array}{l}\text { Em junho, a Suprema Corte dos EUA decide que os serviços de troca de arquivos como o } \\
\text { Grokster e o Morpheus podem se responsabilizados se eles encorajarem usuários a trocar } \\
\text { arquivos protegidos por direitos autorais. }\end{array}$ \\
\hline & $\begin{array}{l}\text { Em setembro, a Som Livre desiste das operações de venda pela internet e vende sua loja } \\
\text { virtual, a somlivre.com, para a Videolar. A ação fora direcionada pelos acionistas que } \\
\text { decidiram estreitar o foco de seus negócios na gravadora, encerrando, assim, suas operações } \\
\text { na internet. }\end{array}$ \\
\hline
\end{tabular}




\begin{tabular}{|c|c|}
\hline \multirow[t]{2}{*}{2006} & $\begin{array}{l}\text { Em maio, o portal sueco The Pirate Bay, uma das maiores fontes para download } \\
\text { de conteúdo ilegal na internet, tem seus computadores confiscados pela polícia. Os criadores } \\
\text { do site são presos, interrogados pela polícia e, dois dias depois, o site volta ao ar. Em } \\
\text { setembro, as gravadoras Universal e EMI anunciam que iriam oferecer música de graça de } \\
\text { seus artistas, entre eles U2, ColdPlay e Radiohead, na rede, via serviço SpiralFrog. No } \\
\text { mesmo mês, o site de troca de arquivos eDonkey paga multa de US } \$ 30 \text { milhões e sai do ar. }\end{array}$ \\
\hline & $\begin{array}{l}\text { O grupo de mídia português "Impresa" fechou a compra, por dois milhões de euros, da Som } \\
\text { Livre, empresa que até então fazia parte dos ativos da rede Globo. Em virtude do grande } \\
\text { aumento da pirataria e do download ilegal de músicas, a Som Livre aposta no relançamento } \\
\text { de álbuns antigos de CDs e DVDs ao vivo como forma de estimular as compras. }\end{array}$ \\
\hline \multirow[b]{2}{*}{2007} & $\begin{array}{l}\text { O jornal O Estado de São Paulo anuncia que a venda de músicas digitais cresceu } 185 \% \text { em } \\
\text { relação ao ano anterior, entretanto os números do mercado físico não são bons. A internet fez } \\
\text { a indústria mundial do disco mergulhar numa crise da qual nunca se recuperou. Apesar do } \\
\text { sucesso nas vendas de música digital, ainda não existe um modelo de negócios consolidado e } \\
\text { capaz de substituir a venda de discos físicos. }\end{array}$ \\
\hline & $\begin{array}{l}\text { A Som Livre persiste na estratégia de relançamento de álbuns antigos e shows ao vivo, como } \\
\text { forma de estimular as compras. Continua com articulações e parcerias com empresa que } \\
\text { permitem o download pago de toques para celular. A Impresa ampliou seu faturamento em } \\
146 \% \text { em relação ao ano anterior, no que diz respeito ao segmento de audiovisual (que } \\
\text { engloba as receitas da Som Livre e da GMTS), alcançando uma cifra de } 9,3 \text { milhões de euros. }\end{array}$ \\
\hline \multirow{2}{*}{2008} & $\begin{array}{l}\text { A venda de músicas digitais continua em franco crescimento e, segundo estatísticas, cresce } \\
\text { mais } 150 \% \text { no Brasil em relação ao ano anterior. Apesar disso, a venda de músicas digitais } \\
\text { representa apenas } 15 \% \text { da receita fonográfica mundial e a nova forma não compensa a queda } \\
\text { na venda de CDs. De acordo com a Associação Brasileira de Produtores de Discos, para cada } \\
\text { música baixada legalmente na rede, outras } 20 \text { são cópias ilegais, ou seja, pirataria. A média } \\
\text { mundial, de acordo com a EEF (Eletronic Frontier Foundation), é ainda pior - } 40 \text { vezes o } \\
\text { número de canções compradas legalmente. }\end{array}$ \\
\hline & $\begin{array}{l}\text { Depois de três anos de retração, gravadoras voltam a crescer no Brasil e o faturamento } \\
\text { aumentou 6,5\% em 2008. Segundo um levantamento da Associação Brasileira de Produtores } \\
\text { de Discos (ABPD), referente ao ano de } 2008 \text {, a Som Livre ficou em } 2008 \text { com a terceira } \\
\text { maior fatia do mercado fonográfico brasileiro, 16,5\%, estando na frente de gravadoras } \\
\text { multinacionais como a EMI Music }(15,01 \%) \text { e a Warner Music }(13,4 \%) \text {. A campeã de } 2008 \text { é } \\
\text { a Universal Music, com 27,3\%, seguida bem de perto pela rival Sony BMG, que teve } 26,9 \% \\
\text { do total. }\end{array}$ \\
\hline \multirow{3}{*}{2009} & $\begin{array}{l}\text { Em abril, a Apple e as grandes gravadoras propõem um sistema de preços de canções } \\
\text { baixadas na iTunes Music em três níveis, como forma de estimular as vendas. Desde sua } \\
\text { inaguração, o iTunes comercializava canções a U\$ } 0,99 \text { cada. A partir de então, os preços } \\
\text { foram flexibilizados em U } \$ 0,69 ; \text { U } \$ 0,99 \text { e U } \$ 1,29 \text {, conforme a canção solicitada. }\end{array}$ \\
\hline & A Som Livre comemora os 40 anos de fundação com uma nova logomarca. \\
\hline & 40 anos \\
\hline
\end{tabular}

Fonte: Elaborado pelos autores com base em pesquisa de noticiário 


\section{Anexo 4}

\section{Comparação produto $\mathrm{x}$ serviço com base nas características de serviços}

\begin{tabular}{|c|c|c|}
\hline Característica & Um CD & O show de um artista \\
\hline Tangibilidade & $\begin{array}{l}\text { Um CD pode ser manuseado, usado } \\
\text { várias vezes, dado de presente e trocado. }\end{array}$ & $\begin{array}{l}\text { De um show, o fã guarda somente as } \\
\text { lembranças. }\end{array}$ \\
\hline Inseparabilidade & $\begin{array}{l}\text { Um CD é produzido em uma fábrica em } \\
\text { Manaus sem a intervenção do } \\
\text { consumidor. }\end{array}$ & $\begin{array}{l}\text { É impossível desvincular a qualidade } \\
\text { de um show da qualidade técnica do } \\
\text { artista. Nessa circunstância, o } \\
\text { consumidor também participa do } \\
\text { serviço. }\end{array}$ \\
\hline Variabilidade & $\begin{array}{l}\text { Dois CDs do mesmo artista comprados } \\
\text { em Recife ou Porto Alegre são } \\
\text { exatamente iguais. }\end{array}$ & $\begin{array}{l}\text { Um show de um mesmo artista pode } \\
\text { ser completamente diferente em duas } \\
\text { cidades e em dois momentos distintos. }\end{array}$ \\
\hline Perecibilidade & $\begin{array}{l}\text { Um CD original } \\
\begin{array}{l}\text { características pantém por } \\
\text { um puas }\end{array} \\
\text { indeterminado. }\end{array}$ & $\begin{array}{l}\text { O show só tem validade na data } \\
\text { estipulada. Após isso, o serviço } \\
\text { perece. }\end{array}$ \\
\hline
\end{tabular}

Fonte: Entrevista 